\title{
La cooperación jurídica internacional en la obtención de prueba $\left.{ }^{*}\right)$
}

\section{POR ERIKA SILVINA BAUGER $(* *)$}

\begin{abstract}
Sumario: I. Introducción. La Cooperación Jurídica Internacional.II. Régimen de la prueba y formas procesales.- III. Aplicaciones concretas a las etapas de la prueba.- IV. Cooperación Jurídica Internacional en la obtención de prueba.- V. Cooperación Jurídica Internacional en la obtención de prueba en la fuente interna y convencional internacional.- VI. Fuente convencional internacional.- VII. Conclusiones.- VIII. Bibliografía.
\end{abstract}

Resumen: la Cooperación Jurídica Internacional es un instituto que pertenece al Derecho Internacional Privado en general y en particular al Derecho Procesal Transnacional. Dentro de los temas que la ocupan y en concreto dentro del proceso civil internacional, se presenta muchas veces la necesidad de diligenciar y producir una prueba en el extranjero. Las reglas de la prueba determinan qué información debe adquirir el juez para resolver el litigio y cómo ha de recogerse dicha información. Esto plantea algunos problemas referidos a la adquisición, transmisión y tratamiento de dicha información. Abordaremos el análisis definiendo el instituto de la Cooperación Jurídica Internacional para luego emprender la delimitación entre los aspectos probatorios sujetos a la lex fori y a la lex causae, para finalizar con el estudio de los problemas procedimentales que plantea la práctica de una prueba en un Estado distinto al que está conociendo en el litigio.

Palabras claves: cooperación - jurídica - internacional - prueba

(*) El presente trabajo fue presentado para el Proyecto de Investigación 11/J154 "Inclusión de la Cooperación Jurídica Internacional en el Código Civil y Comercial de la Nación Argentina”, Facultad de Ciencias Jurídicas y Sociales, Universidad Nacional de La Plata.

(**) Abogada, egresada con Diploma de Honor y Medalla de la UNLP. Premio "Joaquín V. González". Prof. Auxiliar docente con funciones de Adjunta, Cátedra I, Derecho Internacional Privado, Facultad de Ciencias Jurídicas y Sociales, Universidad Nacional de La Plata, UNLP. Becaria de investigación en Iniciación, Perfeccionamiento y Formación Superior de SECyT de la UNLP. Miembro del AADI, ASADIP e Instituto de Derecho Internacional Privado, Colegio de Abogados de La Plata. Integrante de la Red de Profesoras de la FCJyS y del Observatorio de Enseñanza del Derecho de la UNLP. https://orcid.org/0000-0002-6207-4203 


\section{International legal cooperation in obtaining evidence}

Abstract: International Legal Cooperation is an institute that belongs to Private International Law in general, and in particular to Transnational Procedural Law. Within the subjects theyoccupy, and specifically within the international civil process, the need for diligence and producing evidence abroad are often presented. The rules of the test determine what information the judge must acquire in order to resolve the dispute and how to collect such information. This raises some problems related to the acquisition, transmission and processing of such information. We will approach the analysis defining the Institute of International Legal Cooperation and then undertake the delimitation between the evidentiary aspects subject to the lex fori and the lex cause, to end with the study of the procedural problems posed by the practice of a test in a different State to the one who is knowing in the litigation.

Keywords: cooperation - legal - international - evidence

\section{Introducción. La Cooperación Jurídica Internacional}

El instituto es un mecanismo de asistencia entre los Estados que se sustenta en el principio de efectividad, en virtud del cual se confiere eficacia a los decisorios jurisdiccionales aún fuera de sus límites territoriales. Este tópico comprende toda la actividad de naturaleza procesal llevada a cabo en un proceso tramitado o a ventilarse ante un Estado extranjero, de modo que incluye las medidas de cooperación de primer grado, tales como información del derecho extranjero, los actos de mero trámite como las intimaciones, citaciones, etc., el diligenciamiento de pruebas a solicitud de autoridades extranjeras; la cooperación de segundo grado, como la traba de medidas cautelares, el reconocimiento y ejecución de laudos arbitrales extranjeros; y la cooperación de tercer grado, que comprende todas aquellas medidas de seguridad vinculadas a la protección de personas.

Siguiendo a la Dra. Rapallini (2017), la cooperación jurídica internacional es un mecanismo de ayuda entre los Estados, tendiente a afianzar los principios de certeza y seguridad jurídica, otorgando efectividad a los decisorios emanados de autoridades locales y que requieren de ser cumplidos fuera de su territorio, esto es, fuera de su ámbito nacional. Así, un Estado llamado requirente convoca a otro denominado requerido, quien prestará la colaboración necesaria para el cumplimiento del objeto encomendado, bajo las máximas de reciprocidad e igualdad de trato procesal.

Quintín Alfonsín (1982) señala que la cooperación judicial en sentido amplio comprende tres capítulos tradicionales: 1) la atribución o distribución de competencia internacional entre las judicaturas de los Estados; 2) el cumplimiento extraterritorial de medidas procesales dictadas por la judicatura de un Estado; 3) el 
reconocimiento y la ejecución extraterritorial de las sentencias pronunciadas por los jueces de un Estado extranjero.

Cabe destacar, sin embargo, que la expresión "judicial" utilizada por el autor uruguayo resulta insuficiente, ya que si bien el acto cooperativo ha de tener por objeto una rogatoria jurídica - pudiendo referirse a cualquier rama del derechono ha de ser siempre requerida por un juez, quedando habilitadas otras autoridades como las administrativas y las diplomáticas.

Adentrándonos en el tema propuesto, cabe destacar que la cooperación es un mecanismo idóneo de ser empleado tanto en un proceso civil internacional como en uno interno. En virtud de que la jurisdicción de un juez se circunscribe a determinada porción de su territorio y no puede ejercerla más allá, sucede algunas veces que es necesario practicar un acto procesal en algún lugar diverso de dicho territorio, en cuyo caso es forzoso acudir a la autoridad judicial competente solicitando su cooperación. La cooperación se efectiviza cuando los jueces del proceso solicitan a otros jueces que les ayuden a su tramitación, por ejemplo, notificando resoluciones a personas domiciliadas en la jurisdicción de estos últimos, o tomando declaración a testigos en análoga situación.

\section{Régimen de la prueba y formas procesales}

El régimen de la prueba se vincula tanto al Derecho Procesal como al Derecho Material, planteando problemas de delimitación normativa. Cuando los tribunales argentinos deban resolver el fondo del litigio conforme a un ordenamiento extranjero han de delimitar qué aspectos de la prueba deben considerarse como procesales y qué aspectos deben considerarse substanciales o materiales. Esta demarcación es esencial, ya que los primeros quedan sujetos a la lex fori, entendida como la ley que rige el proceso, en nuestro caso, el Derecho argentino; mientras que los segundos vendrán regulados por la lex causae, esto es, la ley material rectora del fondo.

Este problema puede plantearse como un problema de calificación, ya que se trata de calificar una norma o institución como procesal o como material. Por ejemplo, en el Derecho argentino es admisible la prueba genética para determinar la paternidad (artículo 579 del Código Civil y Comercial de la Nación), mientras que en el Derecho islámico la relación filial de parentesco, nasab, mediando matrimonio válido se determina en la presunción de paternidad que tiene en las palabras de Mahoma su justificación última: "el hijo pertenece al lecho" (Martínez Almira, 2006) En un litigio en el que sea aplicable el Derecho islámico a la determinación de la filiación, ¿debe admitir el juez argentino la práctica de pruebas biológicas o no? Si esa regla se calificase como procesal, sí debería hacerlo, pues 
esa cuestión queda sujeta al Derecho argentino. En cambio, si se calificase como material, en mi opinión no - al menos en principio-.

Para resolver los problemas de delimitación entre la lex fori y la lex causae no existe un criterio único y preciso, sino que ha de analizarse cada supuesto concreto. Podemos partir de algunas premisas para realizar el análisis:

a) Las reglas que rigen la prueba se formulan normalmente por razones de índole procesal y ordenatoria y la máxima "lex fori regit processum" indica que las reglas cuya ratio sea procesal y ordenatoria del proceso quedan sujetas al Derecho argentino, lex fori, aun cuando se trate de probar los hechos que configuran el supuesto de una norma extranjera (Virgós Soriano y Garcimartín, Alférez, 2000).

Así, el tribunal argentino que entiende en la causa, aplicará su derecho procesal mediante formas ordenatorias para la consecución e instrucción judicial. La lex fori determinará la estructura del proceso, las distintas instancias, los actos procesales, los plazos, las defensas, los recursos, la caducidad de instancia, las costas, en suma, los principios que deben guiar al juez y a las partes en el proceso.

b) Existen, sin embargo, ciertas reglas sobre la prueba que obedecen a una razón material, en el sentido en que se formulan en atención a las peculiaridades materiales de la norma aplicable o que se vinculan estrechamente a ciertos aspectos no vinculados a la lex fori. En estos casos, tanto la correcta resolución del litigio conforme a la ley material aplicable, así como las expectativas legítimas de las partes, que han configurado su relación material en consideración a esas reglas, indica respetar las normas del Derecho extranjero. Incluimos aquí todos los decisorios que toman contacto con el objeto del proceso, o sea la cuestión de fondo que lo ocupa. La lex fori sufre un recorte y cede lugar a la lex causae, siendo aplicable la ley que rige al acto jurídico materia del proceso (Virgós Soriano y Garcimartín, Alférez, 2000). Es decir, que "por la estrechez que presenta con el acto jurídico que constituye el objeto del proceso es aplicable la misma ley que a este (lex causae). Es necesario observar que no podemos exigir a las partes que prueben acorde a un ordenamiento que carece de vínculo con la relación jurídica cuestionada" (Rapallini, 2017, p. 142).

El lugar donde mejor se puede apreciar esto es a través de un ejemplo. Imaginemos un caso de derecho internacional privado referido a un matrimonio celebrado en el extranjero que tienen su último domicilio conyugal efectivo en la Argentina y que se presenta ante un juez argentino para discutir la validez del mismo. Siendo el caso internacional, el juez argentino deberá constatar si existe una norma atributiva de jurisdicción contenida en la fuente convencional internacional ratificada por nuestro país y que nos vincule con el Estado extranjero de contacto, que le otorgue jurisdicción para entender en el caso. Ello, en virtud de la primacía 
de los tratados internacionales (artículo 75 inc. 22 de la Constitución Nacional) y de lo normado por los artículos 2594 y 2601 del Código Civil y Comercial. El juez argentino solo podrá aplicar las normas de jurisdicción de fuente interna en defecto de norma de fuente internacional aplicable (Fernández Arroyo, 2015)(1). Supongamos que no existe un tratado que vincule a ambos países y el juez argentino recurre a la regla de jurisdicción en materia matrimonial prevista en el artículo 2621 del Código Civil y Comercial, donde se indica que las acciones de validez, nulidad y disolución del matrimonio, deben interponerse ante los jueces del último domicilio conyugal efectivo o ante el domicilio o residencia habitual del cónyuge demandado (2). Siendo que el último domicilio conyugal efectivo ha sido en nuestro país, el juez argentino se atribuye jurisdicción para resolver el caso.

Ahora bien, el derecho aplicable para resolver el caso se encuentra reglado en el artículo 2622 del Código Civil y Comercial de la Nación, que reproduce el artículo 159 del Código Civil de Vélez Sarsfield. En materia de derecho matrimonial se establece:

Derecho aplicable. La capacidad de las personas para contraer matrimonio, la forma del acto, su existencia y validez, se rigen por el derecho del lugar de la celebración, aunque los contrayentes hayan dejado su domicilio para no sujetarse a las normas que en él rigen. No se reconoce ningún matrimonio celebrado en un país extranjero si media alguno de los impedimentos previstos en los artículos 575, segundo párrafo y 403, incisos a), b), c), d) y e). El derecho del lugar de celebración rige la prueba de la existencia del matrimonio.

(1) En la especie los Tratados de Montevideo de Derecho Civil de 1889 y 1940 establecen que los juicios sobre nulidad del matrimonio, divorcio y disolución y demás cuestiones que afecten las relaciones personales de los cónyuges se iniciarán ante los jueces del domicilio conyugal —artículos 62 y 59 respectivamente-. Mientras que en el Tratado de 1889 se dispone que si el matrimonio carece de domicilio deberá tenerse por tal al del marido (artículo 8), en el de 1940 se califica el domicilio conyugal como aquel en donde los cónyuges viven de consuno; luego, y en defecto de convivencia, se dispone que se deberá recurrir al foro del domicilio del marido (artículo 8). En este último, además, se dispone que la mujer abandonada por el marido conserve el domicilio conyugal, salvo prueba de que haya constituido un nuevo domicilio en otro país (artículo 9). Estas disposiciones fueron elaboradas en una época en la que regían otros principios en la materia; sin embargo, esta es aún la legislación vigente. Por ello, creemos que estas normas deberán ser interpretadas y aplicadas a la luz de los derechos humanos recogidos en los tratados de derechos humanos y en nuestra Constitución.

(2) Artículo 2621 CCiv. y Com. "Jurisdicción Las acciones de validez, nulidad y disolución del matrimonio, así como las referentes a los efectos del matrimonio, deben interponerse ante los jueces del último domicilio conyugal efectivo o ante el domicilio o residencia habitual del cónyuge demandado. Se entiende por domicilio conyugal efectivo el lugar de efectiva e indiscutida convivencia de los cónyuges". 
Destacamos que esta norma se aplicará en ausencia de fuente convencional internacional que vincule a la Argentina con el otro Estado involucrado en el caso. Esto, en virtud del artículo 2594 del Código Civil y Comercial, que describe la prelación de fuentes del Derecho Internacional Privado argentino(3), en consonancia con lo normado por el artículo 75 inc. 22 de nuestra Constitución Nacional. (4) En la especie, los Tratados de Montevideo de Derecho Civil de 1889 y 1940 establecen en los artículos 11 y 13, respectivamente, que la capacidad para contraer matrimonio, la forma del acto y la existencia y validez de aquel se someten a la ley del lugar de su celebración. Como sostiene Nieve Rubaja (2015:360), “(...) si el matrimonio se ha celebrado en un Estado parte y aquel cumple con los requisitos de ese lugar entonces, en principio, el matrimonio deberá ser reconocido y desplegar sus efectos en los demás Estados partes".

La nueva disposición es más clara en cuanto al ámbito de aplicación de la norma. A diferencia del artículo 159 del Código de Vélez se detallan cuáles son las condiciones de validez intrínsecas y extrínsecas del matrimonio: la capacidad de las personas para contraer matrimonio, la forma del acto, su existencia y validez. Asimismo, se contemplan en el mismo artículo las soluciones del derecho aplicable a los problemas derivados de la validez y el desconocimiento de los matrimonios celebrados con algunos de los impedimentos contemplados legalmente y la prueba de la existencia del matrimonio en una sola norma (estos dos últimos aspectos eran tratados en los artículos 160 y 161, párr. 1, del Código de Vélez Sarsfield).

El segundo párrafo del artículo 2622 contiene una cláusula especial de orden público en virtud de la cual se faculta a los Estados partes a reconocer, o no, el matrimonio celebrado en uno de ellos cuando se halle afectado alguno de los siguientes impedimentos previstos en el artículo 403 del Código Civil y Comercial: a) el parentesco en línea recta en todos los grados, cualquiera que sea el origen del vínculo; b) el parentesco entre hermanos bilaterales y unilaterales, cualquiera que sea el origen del vínculo; c) la afinidad en línea recta en todos los grados; d) el

(3) El artículo 2594 del Código Civil y Comercial establece: "Normas aplicables. Las normas jurídicas aplicables a situaciones vinculadas con varios ordenamientos jurídicos nacionales se determinan por los tratados y las convenciones internacionales vigentes de aplicación en el caso y, en defecto de normas de fuente internacional, se aplican las normas del derecho internacional privado argentino de fuente interna".

(4) Aun cuando el Código de Vélez Sarsfield nada decía, e incluso antes de la reforma constitucional de 1994, la Corte Suprema de Justicia de la Nación en el caso "Ekmedjian c. Sofovich" (07/07/1992), con sustento en el artículo 27 de la Convención de Viena sobre el Derecho de los Tratados de 1969, reconoció la primacía de los tratados internacionales frente a un eventual conflicto con una disposición interna. Esta doctrina fue confirmada en el fallo "Fibraca Constructora c. Comisión Técnico Mixta de Salto Grande" (07/07/1993). Con la reforma constitucional de 1994 se establece en el artículo 75 inc. 22 la jerarquía supralegal de los tratados internacionales y concordatos con la Santa Sede y la jerarquía constitucional de los tratados de derechos humanos. 
matrimonio anterior, mientras subsista; e) haber sido condenado como autor, cómplice o instigador del homicidio doloso de uno de los cónyuges; a lo que se le agrega el impedimento establecido en el artículo 575, segundo párrafo: “(...) Cuando en el proceso reproductivo se utilicen gametos de terceros, no se genera vínculo jurídico alguno con estos, excepto a los fines de los impedimentos matrimoniales en los mismos términos que la adopción plena". Es decir, cuando hay una vinculación genética por empleo de gametos de terceros entre la persona nacida por este medio y el donante, en los mismos términos que la adopción plena.

Siguiendo a Rapallini (2017, p. 207) "con lo transcripto surge que los requisitos extrínsecos e intrínsecos para la celebración de un matrimonio eficaz continúan sometidos al derecho vigente en el lugar de su celebración. En consecuencia, la prueba del mismo está comprendida en el mismo plexo".

La prueba de la existencia del matrimonio celebrado en el extranjero se rige por el derecho del lugar de celebración. Si bien en nuestro ordenamiento, los artículos 416 a 423 regulan la forma de celebración del matrimonio y su prueba, esta forma prescripta tiene carácter de requisito esencial para la validez de matrimonios celebrados en el país. "La exclusión de toda otra forma de celebración para matrimonios celebrados en el país no juega para supuestos de reconocimiento en Argentina de matrimonios celebrados en el extranjero" (Pallarés, 2015, p. 862).

El sentido del precepto del artículo 2622 del Código Civil y Comercial de la Nación es proteger las expectativas legítimas de las partes, quienes confiaron en la validez formal del acto jurídico y en la posibilidad de probar extraterritorialmente dicho acto. Por ello, no deben verse sorprendidas por la intervención de la lex fori exigiendo un medio de prueba distinto para dicho acto. Por eso los contrayentes deberán probar el matrimonio ante el juez argentino, conforme al derecho material del Estado donde se celebró el matrimonio. El juez argentino no podrá exigir a las partes que prueben el matrimonio conforme a un ordenamiento distinto al de la relación jurídica materia del juicio. No se va a poder exigir que las partes que celebraron el matrimonio en el extranjero, le acompañen un acta de celebración con los requisitos impuestos por nuestro ordenamiento jurídico para considerarlo válido. Aquí, la lex causae, la ley que rige el acto jurídico materia del proceso determina la forma de probarlo(5).

(5) Criterio que había admitido esta solución con anterioridad a la reforma del Código Civil en los fallos: "Kravetz, Linda", aplicación de las normas más favorables a la validez del matrimonio (J.A., 1942-III-310); “Carubin, Dolores" (J.A., Doctrina. 1973-485). En la causa “Solá”, la Corte Suprema de Justicia de La Nación se expidió sobre la aplicación de los impedimentos y el funcionamiento del orden público en orden a permitir la producción de efectos extraterritoriales al matrimonio celebrado en el extranjero (CSJN, 12/11/1986, J.A., 3/12/97). 
Este es el criterio adoptado por los artículos 2 de ambos Tratados de Derecho Procesal Internacional de Montevideo de 1889 y 1940, donde se pone de relieve que la admisión de la prueba sigue a la ley del acto jurídico con el límite de aquel medio probatorio ajeno a la ley del lugar donde se sigue el juicio (6).

\section{Aplicaciones concretas a las etapas de la prueba}

A continuación, vamos a ver como juegan estas consideraciones en las diferentes etapas del régimen de prueba: ofrecimiento, producción y valoración de la prueba.

\section{III.1. Ofrecimiento de la prueba}

Por la estrechez que presenta con el acto jurídico que constituye el objeto del proceso, es aplicable la ley que rige al mismo, esto es, la lex causae.

Al respecto, Devis Echandía (1970, p. 25) define a la prueba como "el conjunto de motivos o razones que nos suministran el conocimiento de los hechos, para los fines del proceso, que de los medios aportados se deducen". Couture (1993, p. 215), por su parte, sostiene que “(...) en su acepción común, la prueba es la acción y el efecto de probar, y probar es demostrar de algún modo la certeza de un hecho o la verdad de una afirmación. (...) en sentido jurídico y específicamente en sentido jurídico procesal, la prueba es ambas cosas: un método de averiguación y un método de comprobación".

Para Kielmanovich (2010, p. 25) con sustento en la tesis de Carnelutti (1982, p. 21) y lo sostenido por Morello, Sosa y Berizonce (2003, p. 25),

(...) la prueba judicial, en sentido estricto, es un procedimiento para la fijación de los hechos, aunque, agregamos, de hechos de interés para la litis no admitidos expresamente o admitidos pero indisponibles, a partir de las concretas fuentes (personas o cosas) que el ordenamiento determina o autoriza en la especie, con abstracción de que el mismo hubiese alcanzado o no para formar la convicción del juez acerca de

(6) El Tratado de Derecho Procesal Internacional de Montevideo del 11 de enero de 1889 establece en el artículo 2: "Las pruebas se admitirán y apreciarán según la ley a que esté sujeto el acto jurídico, materia del proceso. Se exceptúa el género de pruebas que por su naturaleza no autorice la ley del lugar en que se sigue el juicio". El Tratado de Derecho Procesal Internacional de Montevideo del 19 de marzo de 1940, establece en su artículo 2: "Las pruebas se admitirán y apreciarán según la ley a que esté sujeto el acto jurídico materia del proceso. Se exceptúan aquellas pruebas que por su naturaleza no están autorizadas por la ley del lugar en donde se sigue el juicio". 
su probable existencia o inexistencia, según reglas de la sana crítica o libre convicción, o las reglas de la prueba legal, tasada o tarifada.

El objeto de la prueba son los hechos que, afirmados por las partes, constituyen el fundamento de sus pretensiones materiales. Siguiendo a Palacio (1993, p. 481), "en principio, solo los hechos afirmados por los litigantes pueden constituir objeto de prueba. Pero aquellos deben ser, además: a) controvertidos, o sea afirmados por una de las partes y desconocidos o negados por la otra (afirmación unilateral); b) conducentes para la decisión de la causa". Pues bien, en la medida en que la lex causae es la que define los supuestos fácticos de esas pretensiones materiales, el objeto de la prueba y su ofrecimiento solo puede determinarse por dicha ley.

Para Jorge L. Kielmanovich (2010), los hechos desempeñan una triple función: por un lado, sirven como fundamento o causa de la pretensión o la defensa; por otro, se erigen en objeto de la prueba, y por último se establecen como fundamento de las sentencias.

Esta es la definición volcada en el artículo 2 de los Tratados de Derecho Procesal Civil Internacional de Montevideo de 1889 y 1940, donde se pone de relieve que la admisión de la prueba sigue a la ley del acto jurídico con el límite de aquel medio probatorio ajeno a la ley del lugar donde se sigue el juicio.

Esta solución plantea un problema práctico: el juez debe decidir sobre la pertinencia y admisibilidad de la prueba (artículo 364 del Código Procesal Civil y Comercial de la Nación), en función de la lex causae sin tener absoluta certeza de cuál sea esta, ya que en nuestro proceso no hay un juicio previo sobre la ley aplicable al fondo del litigio. Ya que el juez no decide qué derecho aplicar al fondo del litigio hasta que no ha dictado sentencia. El problema debe resolverse interpretando ampliamente el concepto de pertinencia y admisibilidad: una prueba es pertinente y admisible si puede ser relevante a los efectos de cualquiera de los Derechos extranjeros potencialmente aplicables al litigio.

No obstante, la regla de sumisión del objeto de prueba y su ofrecimiento en cuanto a etapa probatoria a la lex causae, conviene hacer un breve análisis de supuestos particulares, como los hechos no necesitados de prueba, las presunciones y los hechos cuya prueba está prohibida.

\section{a) Hechos no necesitados de prueba}

$\mathrm{Al}$ interior de un proceso las partes exponen una serie de hechos controvertidos, los cuales son aquellos afirmados por una de las partes, pero negados por la otra parte. Dentro de esta situación dialéctica existe una división de hechos que la doctrina ha aceptado. Estos son: a) hechos constitutivos: aquellos que producen 
el nacimiento de una situación o derecho subjetivo, como un contrato; b) hechos impeditivos: aquellos que impiden la eficacia de los hechos constitutivos, como los vicios de nulidad en un contrato; e) hechos extintivos: aquellos que extinguen la validez o los efectos de un hecho constitutivo, como la revocación de un poder. En ese sentido, la regla en materia probatoria que debe aplicar el órgano jurisdiccional es, quien alega un hecho constitutivo, impeditivo y extintivo debe probarlo (Kielmanovich, 2010).

En nuestro sistema procesal hay ciertos hechos que no necesitan probarse: los hechos sobre los que exista conformidad de las partes, los confesos y los notorios. El problema estriba en determinar si el régimen de la prueba de estos hechos se aplica el Derecho argentino o el Derecho extranjero.

Destaca Carnelutti (1982, p. 9) que "la afirmación unilateral (discorde) de un hecho es condición necesaria para su posición en la sentencia; la afirmación bilateral (concorde) es, a tal fin, condición suficiente. Los hechos no afirmados no pueden ser puestos, salvo (...) que se trate de hechos notoriamente inverosímiles". De esta afirmación se deprende que los hechos admitidos por las partes no pueden ser objeto de la prueba.

Así, los hechos sobre los que exista conformidad entre las partes y los hechos confesos deben ser considerados por ciertos por el juez argentino. Por regla general, este régimen de prueba queda sujeto a la lex fori en cuanto esa exoneración de prueba no afecta ni modifica el contenido material del Derecho extranjero aplicable, ni se formula en atención a las peculiaridades de la relación litigiosa. Es un régimen de prueba que se justifica en atención a uno de los principios generales del proceso: el principio dispositivo. Y, asimismo, por razones de practicidad, oportunidad procesal y ahorro en el costo de la instrucción responde a una razón procesal ordenatoria sujetándose a la regla lex fori regit processum.

Los hechos notorios para el derecho argentino no necesitan ser probados. Conforme el clásico principio en la materia - notoria non egent probatione - quedan fuera del objeto de prueba (Devis Echandía, 1970, p. 214). Para Kielmanovich (2010, p. 52) "que los hechos notorios no requieren de prueba", se encuentra implícitamente reconocida, a nuestro juicio en el artículo 364 del Código Procesal Civil y Comercial de la Nación (artículo 362, CPBA) en cuanto ordena que no serán admitidas pruebas "manifiestamente improcedentes o superfluas o meramente dilatorias".

Nuestra Corte Suprema de Justicia de la Nación sostiene que el concepto de notoriedad procura dos altos fines de política procesal: "por una parte, un ahorro de esfuerzos al relevar a las partes de producir pruebas innecesarias" y por otra, "procura prestigiar la justicia evitando que esta viva de espaldas al saber común 
del pueblo y su arte consista, como se ha dicho, en 'ignorar jurídicamente lo que todo el mundo sabe"' (7). Véase, asimismo, (Couture, 1993, p. 233), (Calamandrei, 1945, p. 181), (Carnelutti, 1982, p. 15).

Este principio de economía procesal queda sometido a la lex fori. Es una regla que no responde a una ratio iuris material, sino que se vincula a una resolución eficiente del litigio (8).

\section{b) Presunciones}

Una presunción legal tiene como objeto sustituir la prueba de un hecho (hecho presumido) por otro (indicio). De tal forma, que quien prueba este indicio queda exonerado de probar el hecho presunto - artículo 163 del Código Procesal Civil y Comercial de la Nación- (Kielmanovich, 2010). Entonces, las presunciones legales, tanto si son iuris et de jure como si son juris tantum, quedan sujetas a la lex causae, la ley que rija el acto jurídico. Y esta solución se justifica en que las presunciones, si bien tienen como fin facilitar la prueba, modifican directamente el supuesto de hecho que configura el derecho material, en virtud de que el hecho indiciario ocupa el lugar del hecho presunto; y, además, el contenido concreto de una presunción legal tiene como objeto obedecer a razones materiales, favorecer un resultado material: imponer una determinada conducta. Así, por ejemplo: el artículo 566 del Código Civil y Comercial de la Nación(9) establece una presunción de filiación de naturaleza sustantiva, pues, además de establecer quiénes son los padres si se dan ciertos presupuestos, se justifica en atención a la especificidad de la relación material litigiosa - hijos nacidos después de la celebración del matrimonio y hasta los trescientos días posteriores a la interposición de la demanda de divorcio o nulidad de matrimonio, de la separación de hecho o de la muerte-. Estas reglas deben calificarse como materiales y, por tanto, sujetas a la lex causae.

(7) Corte Suprema de Justicia de la Nación en Fallos: 327:4495; 328:690 y en la causa M.2771.XLI "Massa, Juan Agustín c/ Poder Ejecutivo Nacional - dto. 1570/01 y otro s/amparo - ley 16.986", fallada el 27 de diciembre de 2006. "Rinaldi", Fallos: 330:855, entre otros.

(8) Ver fallo del Juzgado de Familia No 2, Mendoza, 09/11/10, “C. A. V. y otro. Adopción internacional." Adopción simple otorgada en Haití. Reconocimiento de sentencia. Legalización. Terremoto. Eximición. Exceso ritual manifiesto. Conversión en adopción plena. Convención sobre los Derechos del Niño, donde el tribunal mendocino aplica la regla del hecho notorio al terremoto en Haití del 12 de enero de 2010. Recuperado de http://fallos.diprargentina.com/2011/02/c-v-y-otro.html

(9) Artículo 566 del Código Civil y Comercial: "Presunción de filiación. Excepto prueba en contrario, se presumen hijos del o la cónyuge los nacidos después de la celebración del matrimonio y hasta los trescientos días posteriores a la interposición de la demanda de divorcio o nulidad del matrimonio, de la separación de hecho o de la muerte. La presunción no rige en los supuestos de técnicas de reproducción humana asistida si el o la cónyuge no prestó el correspondiente consentimiento previo, informado y libre según lo dispuesto en el Capítulo 2 de este Título". 


\section{c) Prueba prohibida}

Hay determinados hechos cuya prueba está prohibida. En estos casos hay que analizar la razón de la prohibición: si la ratio iuris es de naturaleza material deben quedar sometidas a la lex causae; si, por el contrario, la razón de la prohibición es procesal deben quedar sometidas a la lex fori.

Por ejemplo, la regla del artículo 364 del Código Procesal Civil y Comercial de la Nación que no admite las pruebas que fueren manifiestamente improcedentes o superfluas o meramente dilatorias, se formula por razones puramente ordenatorias y por los tanto se aplica la lex fori, sea cual fuera la ley extranjera aplicable al litigio. En cambio, las reglas que prohíben la indagación de hechos cuya investigación o prueba se encuentre prohibida por el ordenamiento jurídico sustancial, aun cuando se relacionen con la materia debatida, se formulan por razones de índole material. Siguiendo a Kielmanovich (2010, p. 59) "aquí no se trata de una prohibición que se establece para vedar el uso de tal o cual medio de prueba, sino de una ilicitud in genere del hecho llamado a erigirse en posible objeto de prueba, nota que excluye por de pronto a todos y cada uno de los medios probatorios". El juez argentino debe calificar esas reglas como materiales y someterlas a la lex causae.

Este caso es distinto de aquellos en que la prueba de determinados hechos venga prohibida por una regla de preclusión o de cosa juzgada. En su caso tales situaciones que hacen a lo procesal y ordenatorio quedarán sujetas al Derecho argentino, la lex fori.

\section{III.2. Producción de la prueba}

Las reglas sobre la producción de la prueba hacen al aspecto procedimental, siendo una forma ordenatoria más y, por ende, sujeta a la lex fori.

La prueba debe ser producida por las partes acorde a las reglas que hacen a la carga de la prueba, cuyas funciones son repartir la tarea de aportación de pruebas entre las partes, e indicar al juez qué respuesta material debe dar cuando no tiene certeza sobre los hechos que fundamentan la pretensión han ocurrido o no (cláusula de prohibición de non liquet). El régimen aplicable sobre estos aspectos es el regulado por la lex fori, su razón es que el proceso es un mecanismo de resolución de conflictos practicable y funcional. 


\section{III.3. Valoración de la prueba}

La etapa de merituación, apreciación o valoración de la prueba, al estar vinculada al derecho material, apunta al contenido del proceso y de ella dependerá la sentencia que se dicte. En esta etapa rige igual ley que la aplicable al acto jurídico y por tanto se aplica la lex causae.

La lex causae establece las reglas de valoración legal de la prueba fundada en razones materiales vinculadas al objeto del proceso y en atención a las peculiaridades de la relación material litigiosa.

Siguiendo con el ejemplo de la filiación paterna y su prueba, el juez argentino al momento de sentenciar deberá respetar una regla de la lex causae según la cual, por ejemplo, para probar la paternidad es suficiente con la confesión judicial del presunto padre, o la que prohibiese valorar en sentido positivo la negativa de someterse a la prueba biológica, en la medida en que se justifica en razones de índole material (estabilidad de las relaciones familiares, tutela de menores, etc.)(10).

\section{Cooperación Jurídica Internacional en la obtención de prueba}

El procedimiento probatorio queda sujeto a la lex fori processum, por consiguiente, en el caso que el litigio se plantee ante los tribunales argentinos, toda la ordenación de actividades procesales del juez y de las partes en materia de prueba deben realizarse conforme al Derecho argentino.

Las dificultades se presentan cuando ese proceso probatorio exige algún tipo de actividad extraterritorial. Por ejemplo, cuando los testigos que tiene que interrogar el juez de un Estado viven en el extranjero, los documentos que se quieren utilizar como prueba están en el extranjero o el bien sobre el que ha de realizarse un reconocimiento judicial o un dictamen pericial está situado en el extranjero.

El primer dato que ha de analizarse es el alcance del derecho fundamental a la prueba que garantiza nuestra Constitución Nacional. Es un corolario del derecho a la jurisdicción que ampara no solo que toda persona pueda ocurrir, en igualdad de condiciones, sin discriminación y en forma efectiva ante un órgano

(10) En materia de determinación de filiación, la admisibilidad o no de la prueba biológica se vincula al ejercicio del derecho material y se hace por motivos de índole material (protección del derecho a la intimidad frente a la protección de los derechos de filiación e identidad); por esta razón deberán ser sujetas a la lex causae. Sin embargo, en la medida que la Constitución Nacional ampara el derecho a la identidad como derecho humano amparando esta prueba, en principio, una ley extranjera que las prohíba sería contraria al orden público argentino. 
jurisdiccional en procura de justicia, sino también la obtención de una sentencia justa y motivada (11).

Bidart Campos (1997), en el mismo sentido, señala que el derecho a la jurisdicción no consiste solamente ni se agota con el acceso al órgano jurisdiccional. Al acudir a él solo se cumple una primera etapa. El desarrollo subsiguiente importa un despliegue del derecho a la jurisdicción que fundamentalmente requiere: a) que se cumpla la garantía del debido proceso, cuyo meollo radica en el derecho de defensa; b) que la pretensión se resuelva mediante la sentencia, que debe ser: oportuna en el tiempo debidamente fundada y justa.

El debido proceso como antecedente lejano, la figura anglosajona del due process of law - receptada por nuestro artículo 18 de la Constitución Nacional-significó la obligación de preservar las garantías que hacen al debido proceso y la carga por parte de los organismos jurisdiccionales de fundar sus decisiones. Cabe señalar que la realización de la justicia y del derecho sustantivo invocados por las partes se debe canalizar necesariamente a través de los órganos, mecanismos jurisdiccionales y formas procesales. El proceso aparece entonces como el nexo permanente entre la regulación normativa de índole abstracta y general y su aplicación a un caso concreto y particular. En este orden, el concepto de proceso está directamente influido por la concepción política vigente en la organización de cada Estado; de tal modo, en un Estado de Derecho las garantías del justiciable deben sustentarse en el respeto de su dignidad humana y la garantía efectiva y real de los valores superiores del ordenamiento jurídico: libertad, justicia, igualdad y paz.

El acceso a la jurisdicción argentina fundamentado en la Constitución Nacional y en las normas de Cooperación Jurídica Internacional (artículos 2611 y 2612 del Código Civil y Comercial de la Nación) conlleva igualmente el acceso a la prueba internacional. Sería manifiestamente incoherente que el sistema jurídico reconociese el derecho del actor a obtener tutela judicial efectiva de los jueces argentinos y la correspondiente carga del demandado de defenderse ante ellos, pero luego impidiese el acceso de las partes a la prueba pertinente por el hecho de estar situada fuera de Argentina.

Siguiendo a Liliana Rapallini, recordemos que el instituto de la cooperación jurídica internacional "es un mecanismo de ayuda entre los Estados, cuya finalidad

(11) Antes de la sanción de la reforma constitucional de 1994 que la incorporó a través de la Convención Americana, este derecho - entendió Padilla - no se desprendía directamente del articulado de la CN 1853/60 aunque lo anticipaba su Preámbulo cuando "incluye entre los objetos del otorgamiento de la Constitución afianzar la justicia, declarando luego en el artículo 18 que es inviolable la defensa en juicio de la persona y de los derechos". 
es afianzar los principios de certeza y seguridad jurídica a través del reconocimiento de decisorios emanados de autoridades locales y que requieren ser cumplidos fuera de su territorio, esto es, fuera de su ámbito nacional. Aquí encontramos, entonces, aquella suma de medidas que escapan para su efectivización a la órbita jurisdiccional local y que, por ende, requieren la colaboración del juez extranjero" (2017, p. 144).

La obligación de cooperación internacional se desprende claramente del artículo 2 de la Carta de Naciones Unidas como un propósito de la Organización que se despliega en diferentes esferas materiales: económica, social, cultural y humanitaria especialmente, asumiendo los Estados el compromiso genérico de adoptar medidas conjuntas o individuales para la realización de los objetivos de la Organización en el artículo 56 de la Carta.

El deber de cooperación es una consecuencia lógica e inevitable de la igualdad de trato, dado que la no cooperación injustificada de las autoridades de un Estado puede significar un obstáculo insalvable y fatal para el ejercicio del derecho al acceso a la justicia (Fernández Arroyo, 2003).

El artículo 2611 del Código Civil y Comercial de la Nación consagra un principio fundamental en esta materia: "sin perjuicio de las obligaciones asumidas por convenciones internacionales, los jueces argentinos deben brindar amplia cooperación jurisdiccional en materia civil, comercial y laboral". Este deber de cooperación en materia civil, comercial y laboral no había sido reconocido con anterioridad como deber general en cabeza de nuestros jueces(12). Es decir que, en estos campos de actuación, el deber de cooperación es incondicional y las autoridades argentinas requeridas solo podrán negarse a cooperar en ausencia de requisitos básicos exigibles o bien que la rogatoria afecte de manera manifiesta y grave algún principio fundamental de nuestro ordenamiento (Fernández Arroyo, 2015, p. 828).

El Código de Vélez no contenía ninguna norma sobre cooperación jurisdiccional. Sin embargo, esta obligación ya había sido asumida por nuestro Estado mediante instrumentos internacionales, tanto bilaterales, como regionales y de carácter universal.

(12) Este principio si se hallaba receptado en materia penal en el artículo 1 de la ley 24.767 de Cooperación Internacional en materia penal que establece: "la República Argentina prestará a cualquier Estado que lo requiera la más amplia ayuda relacionada con la investigación, el juzgamiento y la punición de delitos que correspondan a la jurisdicción de aquel. Las autoridades que intervengan actuarán con la mayor diligencia para que la tramitación se cumpla con una prontitud que no desnaturalice la ayuda". Sin embargo, en esta materia el artículo 3 del mismo cuerpo legal subordina la ayuda a la existencia u ofrecimiento de reciprocidad. Cuestión que no exige el artículo 2611 del Código Civil y Comercial en materias civil, comercial y laboral. 
Esta norma que universaliza una obligación ya asumida por nuestro país al ratificar la fuente convencional internacional en la materia, se articula con el artículo 2612 del Código Civil y Comercial que regula la asistencia procesal internacional:

Sin perjuicio de las obligaciones asumidas por convenciones internacionales, las comunicaciones dirigidas a autoridades extranjeras deben hacerse mediante exhorto. Cuando la situación lo requiera, los jueces argentinos están facultados para establecer comunicaciones directas con jueces extranjeros que acepten la práctica, en tanto se respeten las garantías del debido proceso. Se debe dar cumplimiento a las medidas de mero trámite y probatorias solicitadas por autoridades jurisdiccionales extranjeras siempre que la resolución que las ordena no afecte principios de orden público del derecho argentino. Los exhortos deben tramitarse de oficio y sin demora, de acuerdo a las leyes argentinas, sin perjuicio de disponer lo pertinente con relación a los gastos que demande la asistencia requerida.

\section{Cooperación Jurídica Internacional en la obtención de prueba en la fuente interna y en la convencional internacional}

Teniendo en cuenta estas consideraciones, para estudiar los problemas que plantea la práctica extraterritorial de la prueba distinguiremos dos supuestos: 1) cuando los jueces argentinos están conociendo en el proceso principal y la prueba se encuentra en el extranjero, y 2) cuando el tribunal extranjero está conociendo en el proceso principal y la prueba se encuentra en nuestro país.

Para el análisis tomaremos en cuenta lo normado en la fuente interna y en la convencional internacional. El orden de análisis propuesto se justifica en fines didácticos, por cuanto la primacía de los tratados internacionales, además de estar ordenada claramente por la Constitución Nacional en el artículo 75 inc. 22 y haber sido reiterada muchas veces por la jurisprudencia, ya está prevista en el artículo 2594 que inicia el Título IV Disposiciones de Derecho Internacional Privado y en el artículo 2601 referido a las fuentes de jurisdicción.

\section{V.1. Fuente interna}

\section{V.1.1. Proceso en Argentina y prueba en el extranjero}

Cuando el juicio principal tramita en nuestro país y la prueba (documental, testigos, objeto de reconocimiento judicial, etc.) se halla en el territorio de otro 
Estado, el artículo 369 del Código Procesal Civil y Comercial de la Nación(13), bajo el rótulo de "Prueba a producir en el extranjero" ampara la cooperación jurídica internacional en la producción de la prueba(14).

Así, la prueba que deba producirse fuera de la República deberá ser ofrecida dentro del plazo o en la oportunidad pertinente según el tipo de proceso de que se trate. En el escrito en que se pide deberán indicarse las pruebas que han de ser diligenciadas, expresando a qué hechos controvertidos se vincularán y los demás elementos de juicio que permitan establecer si son esenciales o no.

Solo se contempla la posibilidad que el juez argentino necesite de la cooperación jurisdiccional foránea para la producción de la prueba, en cuyo caso ha de agudizarse la admisibilidad de la ofrecida, en función de los principios de economía y celeridad procesal (artículos 34 inciso 5e y 364). Nada se prevé respecto de la situación inversa, debiendo acudirse al principio general que consagra el segundo apartado del artículo 132 del mismo cuerpo normativo, respecto de las comunicaciones provenientes de autoridades judiciales extranjeras.

Cabe destacar que en nuestra organización político institucional, el derecho procesal y su pertinente reglamentación es materia federal y provincial conforme al territorio de aplicación; y es así, como cada Provincia redacta su propio código de procedimiento que convive con el nacional. De allí en más, los primeros artículos de los códigos procesales resuelven cuestiones de jurisdicción general abordando luego, las propias del proceso y del procedimiento mientras que las jurisdicciones especiales quedaron en manos de la ley de fondo, puntualmente en el Código Civil de Vélez Sarsfield, línea seguida por el actual texto.

Por su parte, el Código Civil sustituido no contenía ninguna norma sobre cooperación jurídica internacional. El artículo 2611 del Código Civil y Comercial opera la universalización de una obligación ya asumida por nuestro Estado respecto de sus jueces mediante instrumentos internacionales, tanto bilaterales como de alcance regional y universal. Nos referimos especialmente a las Convenciones interamericanas y sus Protocolos, en su caso, relativas a Exhortos y Cartas Rogatorias

(13) El Código Procesal Civil y Comercial de la Nación en los artículos 369 y siguientes se refieren a la prueba a producir en el extranjero. "Artículo 369. La prueba que deba producirse fuera de la República deberá ser ofrecida dentro del plazo o en la oportunidad pertinente según el tipo de proceso de que se trate. En el escrito en que se pide deberán indicarse las pruebas que han de ser diligenciadas, expresando a qué hechos controvertidos se vinculan y los demás elementos de juicio que permitan establecer si son esenciales o no".

(14) Aclaro que no trato aquí lo regulado por los Códigos Procesales de las Provincias. Solo expreso que el artículo 367 y siguientes del Código Procesal de la provincia de Buenos Aires prevé un plazo extraordinario cuando la prueba deba producirse fuera de la República. 
(CIDIP I, 1975); Recepción de Pruebas en el Extranjero (CIDIP II, 1979); Cumplimiento de Medidas Cautelares (CIDIP II, 1979); Prueba e Información del Derecho Extranjero (CIDIP II, 1979); Restitución Internacional de Menores (CIDIP IV, 1989); a los Protocolos del Mercosur de Las Leñas (1992) y de Medidas Cautelares (1994) y a las Convenciones de La Haya sobre Notificaciones (1965); Obtención de Pruebas (1970) y Aspectos Civiles de la Sustracción de Menores (1980).

Se trata de una consecuencia lógica e inevitable del derecho a la jurisdicción antes esbozado. En efecto, la no cooperación injustificada de las autoridades de un Estado puede significar un obstáculo insalvable para el ejercicio del derecho al acceso a la justicia. El artículo 2611 deja sentado el principio, pero no desarrolla las vías concretas por las cuales el mismo se desarrolla. La razón posible es que el principio es material y su desarrollo podría incursionar en lo puramente procesal con las dificultades constitucionales que ello supone.

Distinto es lo referido al alcance de la obligación de cooperación, la cual podría haberse precisado de alguna forma. El artículo establece la obligación de los jueces argentinos de cooperar en materia civil, comercial y laboral, más allá de las obligaciones que surjan en tal sentido de los marcos convencionales vigentes. Asimismo, al establecer el alcance de dicha cooperación se ha determinado que esta debe ser amplia. En tal sentido entendemos que, si bien la norma está dirigida a los jueces argentinos, esta debe ser extensiva a todos los que puedan ofrecer este tipo de cooperación en el proceso de que se trate.

La cooperación es extensiva a toda cuestión comprendida dentro del ámbito de aplicación material que delimita la disposición. También esta cuestión debe ser interpretada en sentido amplio. Este margen amplio de cooperación abarcará tanto los actos que resulten necesarios en torno a cuestiones procesales - y que en gran medida coadyuvarán a la concreción del derecho de acceso a la justiciacomo aquellos que estén orientados a cierta finalidad de tipo material y que permitirán realizar derechos fundamentales (por ejemplo, en materia de protección de niños). Además, si bien en materia de restitución internacional de niños en el artículo 2642 del Código Civil y Comercial de la Nación se contemplan algunas medidas de cooperación específicas, lo que exceda dichas previsiones sin lugar a dudas entrará dentro del ámbito de aplicación del presente artículo. Asimismo, el principio de cooperación que emana de este artículo servirá de base para el otorgamiento de informes de idoneidad de residentes argentinos para adoptar en el extranjero como para el seguimiento de dichas adopciones.

En cuanto al artículo 2612 referido a Asistencia Procesal Internacional, cabe destacar que el Código Civil de Vélez Sarsfield no poseía una disposición de estas características. Sin embargo, varias de las fuentes internacionales contemplan la asistencia procesal internacional que abarca este artículo, especialmente el Protocolo de Las Leñas (1992) (artículos 8 y 12). 
El exhorto es la vía por la cual se efectuará la petición de colaboración o asistencia procesal internacional y es el recurso principal elegido en la presente disposición. La elección exclusiva del exhorto como medio para vehiculizar las comunicaciones dirigidas a autoridades extranjeras podría haber estado acompañada de una descripción de los mecanismos concretos de transmisión de aquel. Esto hubiera sido útil sobre todo tomando en cuenta que esta norma se aplicará en ausencia de una convención internacional aplicable.

En general, la transmisión de estos instrumentos puede realizarse por diferentes vías - a través de agentes diplomáticos o consulares, por las propias partes interesadas, por funcionarios judiciales u organismos administrativos especializados, por autoridades centrales, entre otros-. Cuando exista un marco normativo que indique el modo de transmisión de los exhortos, aquel deberá ajustarse a dicha vía; cuando se carezca de dicho marco o directiva deberá optarse por el medio disponible más expedito y, según las circunstancias del caso, que implique menores costos. Cabe resaltar que la disposición se refiere a las comunicaciones dirigidas a autoridades extranjeras y no meramente judiciales, lo que importará un mayor margen para posibilitar la asistencia según cuales sean las autoridades a las que se deba solicitar auxilio.

Las comunicaciones judiciales directas están contempladas para ser utilizadas por los jueces argentinos en ciertas condiciones. Las ventajas de utilización de este recurso son numerosas: permitirán mayor celeridad, menores costos, mayor certidumbre, mayor efectividad, entre otros. Este tipo de práctica permitirá al juez acceder a información de tipo general - por ejemplo, respecto del derecho del Estado requerido, particularidades de sus procedimientos, viabilidad del pedido de asistencia procesal internacional, sistemas de protección existentes-como también se le facilitará la posibilidad de conocer circunstancias respecto de casos concretos - por ejemplo, información respecto de procedimientos que se lleven a cabo en el otro Estado, pruebas producidas, informes, etc.- - La celeridad de este recurso puede resultar vital para el caso concreto, siendo que, por oposición, el exhorto seguramente insuma demoras mayores con consecuencias en perjuicio de los derechos de los sujetos involucrados. Sin embargo, su empleo no podrá ir en detrimento de los derechos de las partes. Es por ello que el límite que impone el legislador para el empleo de este recurso es que se respeten las garantías del debido proceso.

\section{V.1.2. Proceso en el extranjero y prueba en Argentina}

El artículo 2612 del Código Civil y Comercial contempla en su segundo párrafo el supuesto en que el proceso principal tramita en el extranjero y la prueba deba instrumentarse en nuestro país. 
La disposición se refiere a las respuestas que brindarán las autoridades judiciales nacionales frente a la solicitud de asistencia procesal internacional proveniente de autoridades de otros Estados. Así, se pone el énfasis en las medidas de mero trámite y probatorias estableciendo las cualidades de oficialidad y celeridad dentro de lo que esto signifique según el derecho local aplicable. El límite para brindar la asistencia solicitada se encuentra en los principios de orden público de derecho argentino y que, de corresponder, el solicitante cubra los gastos motivados por el cumplimiento de la cooperación.

El juez deberá ser muy estricto en la interpretación y aplicación de ambas condiciones, considerando el carácter constitucional de la obligación de cooperación.

En función de síntesis, señalamos que la realidad sociológica de nuestro ordenamiento jurídico muestra un espíritu amplio de auxilio jurisdiccional en la materia.

\section{Fuente convencional internacional}

Limitaremos el análisis a algunas convenciones específicas en la materia. Así, los Tratados de Derecho Procesal Internacional de Montevideo de 1889 y 1940, las Convenciones Interamericanas relativas a Exhortos y Cartas Rogatorias (CIDIP I, 1975); Recepción de Pruebas en el Extranjero (CIDIP II, 1979); Prueba e Información del Derecho Extranjero (CIDIP II, 1979); el Protocolo del Mercosur de Las Leñas (1992) y las Convenciones de La Haya sobre Notificaciones (1965) y Obtención de Pruebas (1970).

El régimen de los Convenios es muy diverso. Un esquema de aspectos comunes ofrece el siguiente resultado, que no exime de la consulta del texto en cuestión:

a) Son convenios interpartes. Salvo excepción, los Convenios de Cooperación solo se aplican entre los Estados ratificantes.

b) La forma de la petición de cooperación (solicitud, comisión rogatoria, exhorto) es determinada por cada convenio. Salvo acuerdo especial entre los Estados, la petición debe hacerse en la lengua del Estado requerido o traducida al mismo (artículo 5 CLH 1965; artículo 4 CLH 1970; artículo 5.b CIDIP I 1975; artículo 5.3.c. CIDIP II 1979).

c) La transmisión de las peticiones de cooperación puede hacerse por una pluralidad de procedimientos alternativos: por vía diplomática, consular, por autoridades centrales, o por transmisión directa entre las autoridades competentes para el acto. Algunos textos permiten, además, a la persona interesada presentar 
directamente la solicitud a las autoridades del Estado extranjero donde sea necesaria practicar la diligencia procesal.

d) Si la petición de cooperación entra dentro del ámbito material, espacial y temporal del convenio, su cumplimiento es obligatorio para el Estado requerido. La petición solo puede denegarse por los motivos enumerados de modo exhaustivo en los convenios. Los motivos de denegación previstos pueden reconducirse a los siguientes: 1) no hay certeza sobre la autenticidad de la solicitud;2) el diligenciamiento de petición no entra en las atribuciones del poder judicial del Estado requerido; 3) el destinatario alega una exención o prohibición legal; 4) el cumplimiento de la petición atenta contra el orden público o contra la soberanía o la seguridad del Estado requerido.

e) El auxilio tiene lugar conforme a la ley del Estado requerido. Sin embargo, los convenios prevén la posibilidad de solicitar que la actuación se lleve a cabo conforme las prescripciones del Estado requirente.

f) El cumplimiento de la petición de cooperación por el Estado requerido no genera una jurisdicción internacional futura del mismo. Cumplir el objeto de la rogatoria no implica el compromiso de reconocer la competencia judicial internacional del órgano requirente, ni de reconocer o ejecutar la sentencia que dictare.

g) En cuanto a las costas de la cooperación el régimen es variado. Los Convenios de La Haya parten de la gratuidad del servicio de cooperación, aunque el Estado requerido tiene derecho a ser reembolsado por el Estado requirente de ciertos gastos. Por ejemplo: gastos derivados de una forma especial en la notificación (artículo 12 CLH, 1965); las indemnizaciones pagadas a testigos o a peritos (artículo 14 CLH, 1970). La CIDIP I sobre Exhortos y Cartas Rogatorias arranca señalando que las costas y gastos serán a cargo de los interesados (artículo 12), empero el Protocolo adicional, morigerando el principio, establece que el procedimiento será gratuito cuando se haga por intermedio de la autoridad central.

\section{Conclusiones}

Hoy se asiste a un significativo auge normativo en materia de regulación de la entreayuda jurídica internacional y de sus cuestiones conexas y ello no es producto del azar. Diversas variables intervinientes inciden en tal realidad. Entre las mismas corresponde destacar muy especialmente el desarrollo de los medios de comunicación internacional - que permiten volúmenes cada vez más significativos de traslados de personas y bienes y la celebración de contratos a distanciaasí como la creciente flexibilización de las fronteras nacionales, consecuencia de procesos de integración e interrelación entre los Estados, no solo a nivel regional, sino también en el ámbito global. Panorama determinante que, en la hora actual, 
demuestra que la dimensión internacional de la vida humana se vea notoriamente acrecida tanto en lo social, cultural, económico, cuanto en lo jurídico, siendo particularmente destacable en dicho ámbito el incremento verdaderamente geométrico de las relaciones privadas internacionales. Acrecentamiento observable no solo en áreas en que, como las relativas a la contratación mercantil internacional era más previsible el impacto internacionalizante, sino también en otras tradicionalmente más recoletas y domésticas, como las atinentes a minoridad y familia.

El enunciado crecimiento de las relaciones privadas internacionales ha determinado un paralelo incremento de los litigios suscitados en torno a las mismas. Por consiguiente, las cuestiones vinculadas al diligenciamiento de la prueba en un Estado distinto del que se tramita el proceso, provocan que la Cooperación Jurídica Internacional sea hipótesis de planteo cada vez más asiduo ante los tribunales y la consulta profesional. Las reglas de la prueba determinan qué información debe adquirir el juez para resolver el litigio y cómo ha de recogerse dicha información. Esto plantea algunos problemas referidos a la adquisición, transmisión y tratamiento de dicha información. En los distintos apartados se abordó el instituto de la Cooperación Jurídica Internacional, emprendiendo la delimitación de los aspectos probatorios sujetos a la lex fori y a la lex causae, dando cuenta de los problemas procedimentales que plantea la práctica de una prueba en un Estado distinto al que está conociendo en el litigio.

El Título IV del Código Civil y Comercial de la Nación relativo a las Disposiciones de Derecho Internacional Privado incorpora, además de la jurisdicción general y de las especiales, reglas relativas a medidas de cooperación y asistencia jurídica internacional que exceden la materia propia de una ley de fondo. Asimismo, se observa la ausencia de regulación de un procedimiento especial a emplearse para la obtención de pruebas en el extranjero. Si bien se incorpora como principio el deber de cooperación, no se desarrollan las vías concretas para hacerlo efectivo, esto implica la necesidad de adecuación y complementación con la fuente convencional internacional y la legislación procesal. Por ello, sería beneficioso contar con una ley nacional sobre proceso civil internacional y cooperación jurídica internacional que resuelva y reglamente en forma expresa el problema de la obtención de la prueba en el extranjero.

La consolidación de la Cooperación Jurídica Internacional como herramienta esencial de la entreayuda entre los Estados depende en gran medida de la firmeza que se otorgue a los documentos que se elaboren. En la medida que la legislación contribuya a negociar en un marco de seguridad, lo que significa que los ciudadanos conozcamos las reglas y sepamos qué ley se aplica a nuestras negociaciones y que, ante un eventual conflicto, las soluciones serán rápidas, económicas, eficaces y justas, invita a apoyar el desarrollo del instituto. 


\section{Bibliografía}

Alfonsín, Q. (1982). Teoría del derecho privado internacional. Uruguay: Idea.

Bidart Campos, G. (1997). Manual de la Constitución reformada. Buenos Aires: Ediar.

Boggiano, A. (1997). Derecho Internacional Privado y Derecho de las Relaciones entre los Ordenamientos Jurídicos. Ius Inter Iura. Buenos Aires: La Ley.

Calamandrei, P. (1961). Estudios sobre el Proceso Civil. Traducción de Santiago Sentís Melendo. Buenos Aires: Editorial Bibliográfica Argentina.

Calvo Caravaca, A. y Carrascosa González, J. (2000). Derecho Internacional Privado. Vol. I. $2^{\text {a }}$ ed. España: Comares.

Carnelutti, F. (1982). La prueba civil. 2ª ed. Traducción de Niceto Alcalá-Zamora y Castillo. Buenos Aires: Depalma.

Couture, E. J. (1993). Fundamentos del Derecho Procesal Civil. $3^{\text {a }}$ ed. (póstuma). Buenos Aires: Depalma.

Devis Echandía, H. (1970). Teoría General de la Prueba Judicial. T. I. Buenos Aires: Zavalía.

Fernández Arroyo, D. P. (2003). El Derecho Internacional Privado en el inicio del Siglo XXI. Cuaderno da Pós-Graduacao em Direito ppgdir/UFRGS. I (II), (p. 218).

Fernández Arroyo, D. P. (2015). Jurisdicción Internacional. En J. C. Rivera y G. Medina (dir.) y M. Esper (coord.), Código Civil y Comercial Comentado. T. VI. Buenos Aires: La Ley, (pp. 799-829).

Fernández Rozas, J. C. y Sánchez Lorenzo, S. (2000). Derecho Internacional Privado. $1^{\text {a }}$ ed. España: Civitas.

Kielmanovich, J. L. (2010). Teoría de la prueba y medios probatorios. Buenos Aires: Rubinzal-Culzoni.

Martínez Almira, M. M. (2006). La filiación materna y paterna en el Derecho islámico. Derecho sustantivo y reformas de los sistemas jurídicos actuales. Feminismo/s. Recuperado de https://dialnet.unirioja.es/servlet/ articulo? codigo=2392302 [Fecha de consulta: 23/11/2015]. 
Morello, A.; Sosa, G. L y Berizonce, R. O. (2003). Códigos Procesales en lo Civily Comercial de la Provincia de Buenos Aires y de La Nación. Buenos Aires: Abeledo Perrot.

Palacio, L. E. (1993). Manual de Derecho Procesal Civil. T. I. 10ª ed. Actualizada. Buenos Aires: Abeledo Perrot. T. I.

Pallarés, B. (2015). Sección 2a Matrimonio. En J. C. Rivera y G. Medina (dir.) y M. Esper (coord.), Código Civily Comercial Comentado. T. VI. Buenos Aires: La Ley (pp. 857-870).

Rapallini, L. E. (2017). Temática de Derecho Internacional Privado. La Plata: Lex.

Rubaja, N. (2015). Sección 2a. Matrimonio. En M. Herrera; G. Caramelo y S. Picasso (dir.) Código Civil y Comercial de la Nación Comentado, Tomo VI. Libro Quinto y Libro Sexto Artículos 2277 a 2671. 1ª ed. Ciudad Autónoma de Buenos Aires: Infojus (pp. 358-372).

Virgós Soriano, M. y Garcimartín Alférez, F. J. (2000). Derecho Procesal Civil Internacional. Litigación Internacional. España: Civitas.

Fecha de recepción: 30-10-2018

Fecha de aceptación: 16-07-2019 